\title{
Application of Project Teaching for Smart Grid Technologies in Postgraduate Practice Innovation Ability Training
}

\author{
Sheng Li, Sijia Lu, Jiani An, and Heng Wu \\ School of Electric Power Engineering \\ Nanjing Institute of Technology \\ Nanjing 211167, China \\ E-mail: lisheng_njit@126.com
}

\begin{abstract}
This paper discussed the basic concepts, topic selection principles, and the assessment methods of project teaching. The application process of CDIO teaching method in project teaching is introduced according to the steps of "Conceive - Design - Implement - Operate", taking the electric vehicle (EV) project training in the smart grid technical scope for example. The project achievements reflect the effect of CDIO project teaching in improving the practical innovation ability of postgraduates majoring in electrical engineering. It is pointed out that the topic of project teaching must be selected from the perspective of engineering and exploratory, the process is independent and guaranteed, and the results are observable and assessable. Compared with the traditional teaching mode, project teaching pays more attention to training students' self-learning ability and practical innovation ability, which helps to cultivate postgraduates with creative thinking and innovative ability.
\end{abstract}

Keywords-Project teaching; Practice innovation ability; CDIO teaching method; Smart gird; Electric vehicle (EV)

\section{INTRODUCTION}

With the rapid development of China's social economy, the country's demand for innovative talents has become increasingly urgent. In recent years, a large number of changes have taken place in the energy structures [1-4], energy and power development modes taking the new energy, smart grid and energy internet as the core have become mainstream mode for the development of power grids and even for household appliances [5-7]. The smart grid industry urgently needs a large number of outstanding electrical engineering graduate students who have higher practical innovation capabilities. The teaching reform of electrical engineering master of professional is imperative.

For many years, the traditional teaching mode of engineering colleges is that teachers pay attention to preaching and teaching, and students only pay attention to memorization and examination. In this process, the students are in a passive state: the passive learning, and the passive acceptance of knowledge. And the accepted knowledge is also limited to a certain extent. Students can not show their personalities, and their practice innovative ability is also consumed by this mechanical teaching mode.
Under the current situation, the new teacher-student relationship between supervisors and graduate students is concentrated in the fact that graduate students conduct innovative work under the guidance and encouragement of their supervisors, that is, carrying out innovative research activities. It is not a true teacher-student relationship that is out of this kind of cooperative relationship which was developed for an innovative goal. And the project teaching is a practical teaching mode to get a better graduate training.

Project teaching takes students as the main body, teachers as guide, and project as centrality. It presents a practical and simplified engineering project to students. Students carry out program design and demonstration in a team-coordinated manner, and complete project tasks through division of labor and collaboration. Through the project teaching, students can develop their abilities of independent learning and collaborative learning, and achieve the goal of cultivating their scientific research capabilities and practice innovative capabilities.

This paper mainly discusses the application of CDIO engineering teaching mode in project teaching and the role of project teaching in improving the practice innovation ability of electrical engineering graduate students.

\section{CDIO PROJECT TEACHING}

The CDIO teaching mode is based on the constructivist teaching theory and proposes an engineering teaching mode which is suitable for engineering practice and innovation ability training. Its goal is to cultivate students' ability to quickly adapt and integrate into the company's team after graduation so that they can create value. CDIO emphasizes engineering is the foundation, and it builds the product and system life cycle to realize the perfect combination of "Conceive - Design - Implement - Operate" process and build engineering education on this basis [8]. 


\section{A. Topics of Project Teaching}

CDIO teaching takes project development as the main line, so it is very suitable for the project teaching of engineering majors. Project topics in CDIO project teaching should be selected from the actual engineering of industry, and it should closely track the latest technology trends. Taking the electrical engineering major as an example, the topic of project teaching should closely track the latest developments of smart grid and energy internet technologies. The scope of the topic selection can be carried out around all aspects of smart grid technologies, including:

1) New energy and clean energy grid-connected technologies;

2) IEC 61850 communication protocol and smart substation technologies;

3) UHV AC/DC transmission technologies;

4) Smart distribution network and microgrid technologies;

5) Intelligent power utilization technologies;

6) Intelligent dispatch technologies;

7) Advanced energy storage technologies;

8) Energy internet and global energy internet technologies.

Based on the professional knowledge, characteristics, and expertise of the students, the project instructor identifies the specific project topics in the above directions, and uses the projects after micro-processing, simulation, and other processing. At the same time, it should also ensure that the project subject has certain explorability, so that students can achieve research-based learning in the project development process so as to achieve the purpose of training practice innovation ability.

In the actual operation of higher-level project teaching, the instructor can only give one hotspot of current technology research, and the student team can design the project topic all by themselves. For example, intelligent power utilization technologies include smart meter, advanced measurement system, smart building, smart home, electric vehicle (EV), and smart electricity information interaction, etc. Students can design the specific project topics based on their own research interests and professional basic.

In the process of project teaching, attention should be paid to maintaining the independence of the student team in completing project tasks, giving full play to their personal abilities and cultivating their teamwork and organizational management capabilities.

\section{B. Assessments for Project Teaching}

Project teaching assessment can be divided into two aspects: process assessment and achievement assessment. It should be ensured that the student team can independently carry out research-based learning and collaborative learning, and be provided with laboratories and adequate opening hours, project funds, basic component consumables, and metering tools during the implementation process of the project. In addition to assessing whether or not the student enters the laboratory to carry out project research at the appointed time, the project instructor needs to guide and evaluate the "Conceive - Design - Implement - Operate" process of the project. However, it should be noted that the instructor only plays the role of mentor in the project development process without too much interference with the specific work process of the student project team.

The achievements of CDIO project teaching should be appraised. That is, the teaching achievements should be a specific physical device or system that can be run and demonstrated, or a software that can be used to demonstrate. The higher-level achievements are the publication of a certain level of papers, patent applications, or software copyrights. They can fully exercise the skills of students to write scientific papers and intellectual property documents. And they also show that the students are good at timely summing up the achievements of project teaching. Graduate students should be encouraged to produce more papers or patent achievements.

\section{CDIO PROJECT TEACHING CASE}

The current postgraduate project training topic "Wireless Charging Device for Electric Vehicles (EVs)" is taken as an example to introduce the application of CDIO engineering teaching mode in the project teaching of electrical engineering from the whole process of "Conceive - Design — Implement - Operate".

\section{A. Project Engineering Technology Background and Concept}

Students take initial ideas while accepting the project task. The concept requires the support of the basic knowledge of the relevant engineering and technology background. It also requires students to actively consult relevant data to demonstrate their own hypotheses, rather than unilaterally instill knowledge by teachers, leading to the neglect of the process of subjective exploration.

As an important part of the smart grid, intelligent power utilization technologies are important guarantee for realizing the interaction between the power grid and users, and the traditional power consumption mode has undergone tremendous changes. Electric vehicle (EV), shown as Figure 1, as one of the concrete realization form of intelligent power utilization technologies, plays an important role in promoting environmental protection and social development, and it is the main direction of future intelligent transportation.

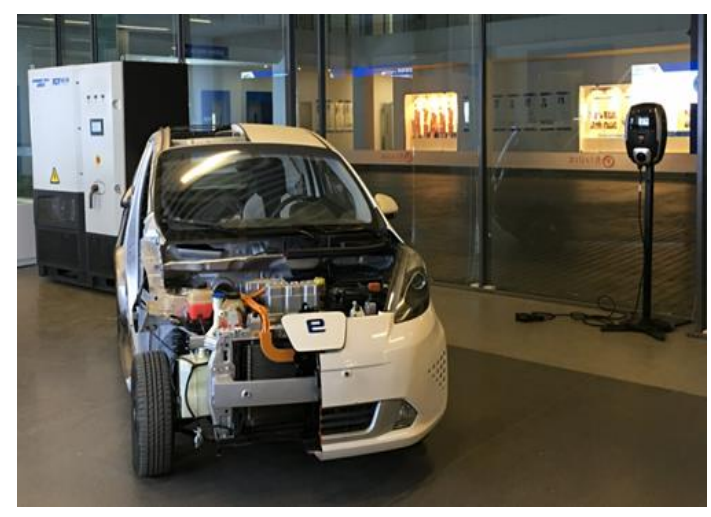

Fig. 1 Electric vehicle (EV) model 
Wireless charging is the transmission of electrical energy through the electromagnetic field. Compared with traditional contact charging methods, wireless charging is more secure and can adapt to a variety of harsh environments and weather. The application of wireless power transmission technology to the wireless charging and discharging of EVs not only solves the problems of various types of charging piles, but also disperses the concentration of charging and discharging of EVs in order to relieve the impact of large-scale charging and discharging of EVs on the power grid, to some extent.

The application of wireless charging and discharging technology can greatly improve the interaction between the EVs and the power grid. Through the intelligent interaction between the two parties, the EVs can be charged and discharged more reasonably so as to suppress the output volatility of renewable energy and increase the transportation and use of renewable energy. The positive effect on smart grid is even more pronounced.

Based on the understanding above, after several rounds of discussions among project instructor and students, it was decided to design and manufacture an electric vehicle charging device based on radio energy transmission technology. The project was successfully established and acquired finance support after the project instructor wrote the syllabus to apply.

\section{B. "Design, Implement and Operate" of EV Project}

Based on the concept of the previous stage, it enters key stages of design, implementation and operation. Graduate students generally lack serious practical skills and need to change from knowledge to application. In the early stage, with the help of the instructor and the cooperation of team members, students can overcome the strangeness of the entry. In the later period, they have to fully display their hands-on practical abilities to apply the concept to practical problems, continuously discover the problems and solve the problems so that they can get qualitative progress.

In the specific implementation stage of the EV project, a project team composed of four graduate students will write an opening report, design a reasonable project technology program, determine the software, hardware and materials needed for the project, and make a budget. Second, to ensure that the project can be completed, division of labor is performed according to each student's specialty and ability. Finally, laboratory resources were provided and fixed research hours of at least 8 hours per week were specified to make the process assessment possible.

Since the project teaching is a simulation of an actual engineering project, the electromagnetic induction type wireless charging method often used for low-power wireless charging was selected when determining the technical solution. The main circuit of the wireless charging device is XKT-801 chip, and the main circuit board is designed using the designer software Altium, as shown in Figure 2.

The process of the project team's production for an electric vehicle wireless charging simulation physical device is shown in Figure 3. Figure 4 shows the working status of the charging device under a certain scenario. In the stages of design, implementation, and operation of the EV project, the project team remained relatively independent, and the instructor did not interfere too much with the specific research process.

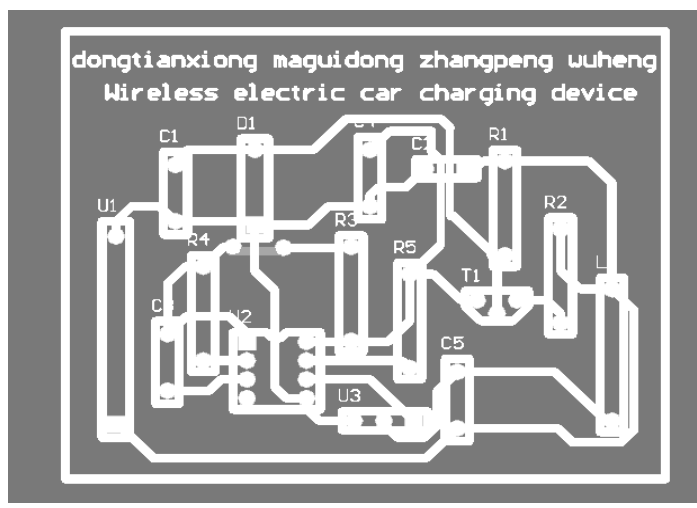

Fig. 2 Main PCB - "Design”

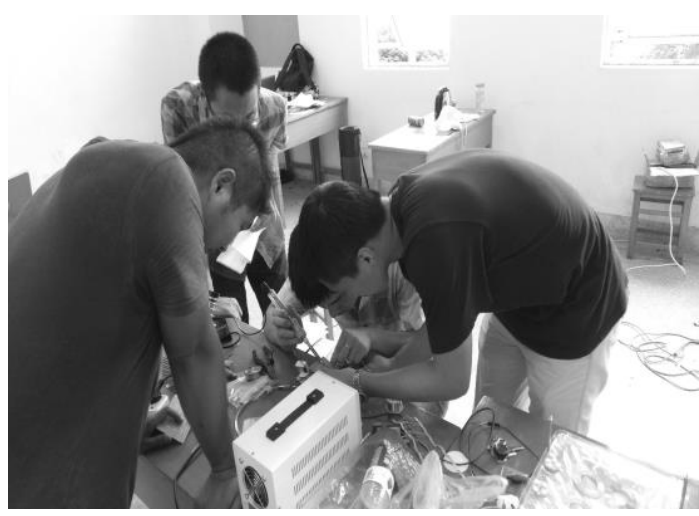

Fig. 3 Device Production - "Implement"

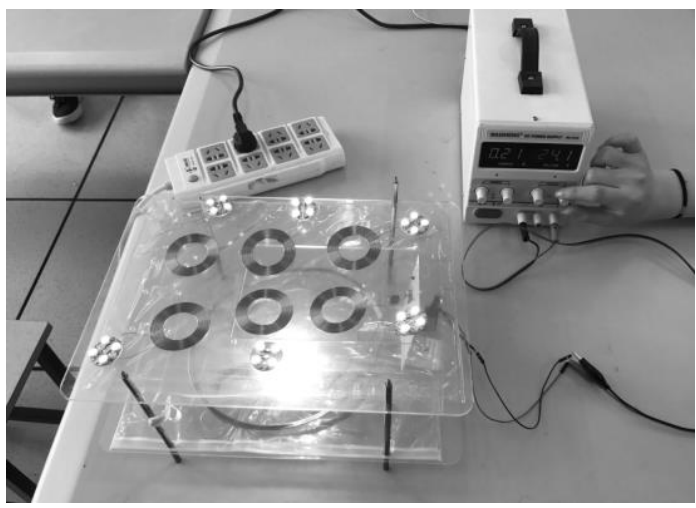

Fig. 4 Device Operation - "Operate" 


\section{Assessments for Project Teaching Achievements}

The evaluation methods for project achievements include the writing of the final report, the assessment of the instructor, and the oral defense of their work facing the expert group. One of the achievements of the EV project is a physical device that can be operated to indicate the principle of operation. In addition, the project students applied for an invention patent as the first inventor, and successfully participated in the Nanjing university undergraduate outstanding patents exhibition in 2017 and won a prize in the "Yuejiang Cup" undergraduate outstanding patents venture project in 2018. The students have a certain potential in college entrepreneurship. The training results of this project can fully reflect the role played by CDIO project teaching in cultivating the practice innovation ability of graduate students majoring in electrical engineering. Students have gained greater training in brains, hands-on ability and writing ability.

\section{CONCLUSION}

From the above analysis, we can get the conclusions that the topic selection of CDIO project teaching should be engineering and exploratory, the process should be independent and guaranteed, and the achievements should be observable and assessable, so as to effectively improve students' practice innovation ability.

We have also successfully applied the project teaching to the training of undergraduate innovative ability. For example, on the basis of the aforementioned work, the EV project succeeded in applying for a 2017 national university student innovation training program. In the past two years, we had instructed students to complete 6 postgraduate and university student innovation projects of the Ministry of Education and Jiangsu Province, and apply for 6 invention patents and 1 computer software copyright. There are 7 patents awarded, 2 utility model patents transferred. And 5 EI indexing papers and 1 paper in Chinese core journals were published. Moreover, the achievements of typical project teaching participated in the college's innovation and entrepreneurship education exhibition in 2017. A teacher was awarded the excellent instructor for innovation and entrepreneurship.

The purpose of project teaching is to allow students to no longer be confined to the traditional teaching mode. Instead of relying on teachers to teach, they can give time to students and allow them to deeply understand and study what they have learned. Find their own specialty and interests in self-learning, collaborative learning and research-based learning. The students thus cultivated must have strong practice innovation and professional competence. Of course, this does not mean that the instructor can completely withdraw from teaching. The knowledge and self-presentation of the students must be limited, and the instructor should be able to provide useful guidance when students encounter a technical bottlenecks. Further, the instructor should provide a reliable platform for students to fully show themselves when they break through.

\section{ACKNOWLEDGMENT}

This work is supported by the Collaboration between Industry and School Synergetic Education Project of National Department of Education, China (201602006022), the Postgraduate Education and Teaching Reform Research and Practice Project of Jiangsu Province (JGLX16_071), and the University Student Innovation \& Entrepreneurship Training Program of Jiangsu Province (201711276009Z).

\section{REFERENCES}

[1] S.S. Refaat, H. Abu-Rub, A.P., Sanfilippo, A. Mohamed, "Impact of grid-tied large-scale photovoltaic system on dynamic voltage stability of electric power grids." IET Renewable Power Generation, vol. 12, pp. 157-164, February 2018.

[2] S. Li, Z. Wei, and Y. Ma, "Fuzzy load-shedding strategy considering photovoltaic output fluctuation characteristics and static voltage stability," Energies, vol. 11, p. 779, April 2018.

[3] S. Li, Z. Wei, Y. Ma, J. Cheng, "Prediction and control of Hopf bifurcation in a large-scale PV grid-connected system based on an optimised support vector machine," The Journal of Engineering, vol. 2017, pp. 2666-2671, January 2017.

[4] R.R. Londero, C.D.M. Affonso, J.P.A. Vieira. "Long-term voltage stability analysis of variable speed wind generators." IEEE Transaction on Power System, vol. 30, pp. 439-447, January 2015.

[5] S. Li, Z. Zhou, Q. Shan, and J. An, "Analysis of transient voltage stability in a low voltage distribution network using SST for the integration of distributed generations," Journal of Electrical and Computer Engineering, in press.

[6] Z. Dong, J. Zhao, F. Wen, and Y. Xue, "From smart grid to enegry internet: basic concept and research framework," Automation of Electric Power Systems, vol. 38, pp. 1-11, August 2014. (In Chinese)

[7] Y. Li, B. Wang, and F. Li, "Outlook and thinking of flexible and interactive utilization of intelligent power," Automation of Electric Power Systems, vol. 39, pp. 2-9, September 2015. (In Chinese).

[8] E. F. Crawley, "Creating the CDIO syllabus, a universal template for engineering education," 32nd ASEE/IEEE Frontiers in Education Conference, Boston, MA, USA, November 6-9, 2002; pp. 1-6. 